\title{
A seleção conceitual na organização de domínios de conhecimento nas ciências humanas e sociais: o caso da cultura
}

\section{Anderson Luiz Cardoso Rodrigues}

Mestre em Ciência da Informação pelo Instituto Brasileiro de Informação em Ciência e Tecnologia (IBICT), em convênio com a Universidade Federal do Rio de Janeiro (UFRJ)

Aborda o aspecto da seleção conceitual na organização de domínios de conhecimento nas ciências humanas e sociais, tomando como foco o conceito de cultura e sua complexidade peculiar. A seleção conceitual é uma etapa inicial da construção de sistemas de organização de conhecimento e mostra-se importante para um resultado final de qualidade, quanto à recuperação da informação. Para evidenciar a complexidade do domínio cultura, são analisadas as origens etimológicas das palavras amazônicas, onde se revelou uma grande diversidade cultural em línguas não-nativas originárias de continentes africano, europeu e asiático. Foi sugerido, como fundamento teórico-metodológico, para lidar com domínios complexos dessa natureza, a Teoria da Classificação Facetada, de Ranganathan e a Teoria dos Níveis Integrativos, do Classification Research Group.

Palavras-Chave: Ciências humanas; Ciências sociais; Cultura; Seleção conceitual; Sistemas de organização do conhecimento. 


\section{Conceptual selection in the organization of knowledge domains in human and social sciences: the case of the culture}

This paper appproaches the conceptual selection in the organization of knowledge domains in the human and social science is approached, focusing on the culture concept and its peculiar complexity. Conceptual selection is an initial stage in system construction in the organization of knowledge and its importance is shown for a final quality result regarding the recovery of information. To show the complexity of the culture domain, the etymological origins of Amazon words are analyzed, where a wide cultural diversity in original nonnative African, European and Asian languages. The Theory of the Faceted Classification by Ranganathan and the Theory of the Integrated Levels from the Classification Research Group were suggested as theorical and methodological basis to deal with complex domains of this nature.

Keywords: Human Science; Social Science; Conceptual selection; System of knowledge organization.

Recebido em 22.04.2010 Aceito em 01.06.2011

\section{Introdução}

Este artigo pretende abordar a seleção conceitual da organização do conhecimento nas áreas das ciências sociais e humanas e, para tanto, nos concentraremos no domínio da cultura. Entendemos que o conceito de cultura é um conceito complexo e muitas escolas de pensamento existem, cujos olhares e pontos de vistas são compreendidos por diversos ângulos.

A complexidade do conceito cultura não é uma singularidade desse domínio, mas, sobretudo, das áreas das ciências sociais e humanas como um todo. Desse modo, consequência da sua dificuldade, seus limites, enquanto domínio especializado do conhecimento, também são delicados, refletindo, portanto, na primeira etapa de construção de um sistema de organização do conhecimento, a seleção e levantamento conceitual.

A seleção inadequada de um sistema de organização do conhecimento especializado pode criar ruídos na recuperação da informação pelo usuário e pelo profissional da informação, que venha a utilizar o sistema para classificação, indexação ou controle e padronização de termos. 
Conceitos importantes podem ficar de fora do corpus terminológico do instrumento e outros podem fazer parte do conjunto de termos sem, no entanto, serem necessários para uma área, sendo inutilizados, uma vez que não compõem o domínio do conhecimento e não se torna de interesse para seus usuários.

Sendo assim, este estudo pretende discutir a organização do conhecimento nas ciências sociais e humanas e o aspecto da seleção conceitual. Para isso, a Teoria da Classificação Facetada, de Ranganthan e a Teoria dos Níveis Integrativos, do Classification Research Group (CRG), de Londres, foram sugeridas como aportes teóricos para a construção em domínios culturais.

Com o intuito de evidenciar a complexidade do domínio cultura e, consequentemente, sua seleção conceitual em um sistema de organização do conhecimento especializado, apresentamos as etimologias das palavras culturais amazônicas. A análise evidenciou o hibridismo cultural na região, cujas influências não nativas na língua local são muito fortes. Corroborando para o argumento da difícil tarefa de estabelecer limites conceituais no domínio.

\section{A complexidade da organização de domínios de conhecimento nas ciências humanas e sociais}

Para Langridge (1977), a organização de domínios do conhecimento, nas ciências humanas e sociais, tem uma diferença profunda em relação às outras áreas. As ciências exatas, por exemplo, tendem a ter um corpo mais harmônico de pensamento, enquanto que nas ciências humanas e sociais há várias teorias e escolas.

Para Maués (1999, p. 16), isso ocorre porque essas áreas lidam com objetos de análise radicalmente diferentes, "que é a sociedade humana, da qual faz parte, como indivíduo e pessoa, o historiador e o cientista social". Quem estuda o objeto é o próprio objeto de estudo, portanto, é mais difícil compreender o todo, quando se é parte dele.

Quando o observador está analisando seu objeto, ele está observando processos dos quais necessariamente participa. Para tanto, são necessários métodos diferentes para estabelecer evidências e interpretações, em relação às ciências naturais e exatas (WILLIAMS, 2008).

Sobre a dificuldade de se trabalhar com assuntos das ciências humanas, Langridge (1977, p. 34) afirma que o classificacionista deve explorar bem o conhecimento com o qual está trabalhando, no entanto, ratifica que é mais fácil analisar as relações entre Física, Química e Biologia do que as relações entre Ciência, Filosofia, História e Arte.

Moraes e Arcello (2000) também destacam que a adaptação dos assuntos contidos nos documentos estipulados nas tabelas de classificação, nas listas de cabeçalhos e nos tesauros provoca insatisfação por parte do profissional responsável pela tarefa de classificação e 
indexação de assuntos, principalmente quando o assunto pertence às ciências sociais.

Segundo Langridge (1977, p. 96), "... as fronteiras entre os vários estudos sociais são difíceis de estabelecer", como consequência, gera-se uma imprecisão conceitual, que reflete na compreensão integral dos conceitos e nas suas relações dentro do sistema, implicando diretamente na estrutura e no desenvolvimento dos sistemas de classificação e recuperação da informação. Esse fator dificulta a tarefa do classificacionista quanto à seleção dos conceitos, que deve compor o universo terminológico de um dado domínio nas ciências humanas e sociais.

\section{O domínio do conhecimento cultura}

Cultura é derivada da palavra latina cultura. É um conceito ligado às ciências humanas e sociais e, portanto, têm conceituações de várias escolas e pensamentos, que foram evoluindo ao longo do tempo. Eagleton (2005) comenta que é uma das duas ou três palavras mais complexas da nossa língua e Willians (2008, p. 10) a considera um conceito "excepcionalmente complexo".

Para Thompson (1995) e Wilians (2008), quanto ao sentido da palavra cultura, existem cinco concepções que foram se modificando ao longo de sua história: a concepção original, a concepção clássica, a concepção descritiva, a concepção simbólica e a concepção estrutural.

A concepção original está ligada ao sentido da origem etimológica da palavra cultura. Nessa primeira concepção, os primeiros sentidos da palavra nos idiomas europeus preservaram o sentido original, que significava cultivo ou cuidado de alguma coisa, como grãos ou animais.

$\mathrm{Na}$ concepção clássica, o sentido original mudou da esfera agrícola para o cultivo da mente. Francis Bacon escreve sobre o cultivo e adubação de mentes, em uma hesitação sugestiva entre estrume e distinção mental. Inicialmente, cultura denotava um sentido puramente material e, depois, metaforicamente foi transferido para questões de espírito (THOMPSON, 1995). Essa concepção surgiu nas primeiras discussões sobre cultura, especialmente entre os filósofos e historiadores alemães, no fim do século XVII. Com o aparecimento da Antropologia, essa concepção perdeu sua força.

A concepção descritiva da cultura refere-se a um variado conjunto de valores, crenças, costumes, convenções, hábitos e práticas características de uma sociedade específica ou de um período histórico. Nessa concepção, o conceito de cultura foi despojado da conotação etnocêntrica. Estava menos ligado ao enobrecimento da mente e do espírito e mais ligadas às práticas e costumes de outras sociedades que não as europeias.

A concepção simbólica focaliza o interesse no simbolismo. Os fenômenos culturais são fenômenos simbólicos e o estudo da cultura está essencialmente interessado na interpretação dos símbolos e da ação 
simbólica. A debilidade dessa concepção se encontra na falta de atenção suficientemente para as relações sociais estruturadas, nas quais os símbolos e as ações simbólicas estão sempre inseridos.

$\mathrm{Na}$ concepção estrutural de cultura, os fenômenos culturais podem ser entendidos como formas simbólicas em contextos estruturados. A análise cultural pode ser pensada como o estudo da constituição significativa e da contextualização social das formas simbólicas.

Thompson (1995), ao apresentar os vários sentidos que o conceito de cultura vem sofrendo ao longo do tempo, conclui que a cultura é um fenômeno cultural, que não é simplesmente uma questão de objetos e fatos que ocorrem no mundo natural, mas, também, uma questão de ações e expressões significativas, manifestações verbais, símbolos, textos e artefatos de vários tipos, e de sujeitos que se expressam através desses artefatos e procuram entender a si mesmos e aos outros pela interpretação das expressões que produzem e recebem. Os fenômenos culturais podem ser pensados como o estudo das maneiras como expressões significativas de vários tipos são produzidas e recebidas por indivíduos situados em mundo sócio-histórico.

Laraia (2006), em seu trabalho, faz um percurso nas principais teses antropológicas sobre questões relacionadas à cultura e destaca quatro. $\mathrm{O}$ determinismo cultural, onde os estudos apontavam as características genéticas como grandes influenciadoras da personalidade humana. 0 determinismo geográfico, afirmando que as diferenças no ambiente físico afetavam a diversidade cultural. A que considera cultura como sistemas estruturais, que define cultura como um sistema simbólico e como uma criação acumulativa da mente humana. E, a última das abordagens, que considera cultura como sistemas simbólicos.

Nunes (2004) divide cultura em três acepções: acepção individual, acepção social e acepção histórica. Na acepção individual, isto é, relativa ao indivíduo, cultura oscila entre dois polos: ou significa o conjunto de conhecimento, de ideias, de crenças e de critérios de valor, com que todo o indivíduo se acha munido e faz uso nas suas relações consigo mesmo e com os outros, ou significa a sua formação, intencional e voluntariamente orientada, com apoio em um variável grau de conhecimentos e experiências acumulados, para alcançar uma maneira estável de pensar e de agir.

No primeiro caso, cultura corresponde ao equipamento mental do indivíduo pela educação recebida e é uma posse intelectual moral ou religiosa, que se alia à personalidade do sujeito. No segundo caso, está mais próxima da origem etimológica da palavra - colere/cultivar - que traduz o cultivo do indivíduo, de sua inteligência e de sua sensibilidade. A cultura, nesse sentido, está unida à personalidade e, mais do que uma posse, representa um modo de ser do indivíduo. Esses dois aspectos do conceito, Nunes (2004) chama de subjetivo, enquanto as outras acepções, a social e a histórica, situam-se no eixo objetivo.

Na acepção social, a cultura é a herança transmitida de geração para geração e de que os indivíduos, como seus usufrutuários, partilham 
diferentemente, conforme o dinamismo dos grupos ou classes a que se vinculam. Pode-se, por exemplo, falar de uma cultura aristocrática ou uma cultura burguesa, designando essas expressões às ideias dominantes de um período ou de uma sociedade.

De acordo com a acepção histórica, a cultura seria a fisionomia intelectual, artística e moral de uma civilização ou de um povo, ao longo de sua história e em um momento dela. Através dessa acepção, poderemos falar de uma cultura ocidental, cultura helênica e cultura brasileira.

Prevalece, então, uma personalidade espiritual distintiva de determinado povo, a cultura depende de uma acumulação e de uma transmissão no tempo com modificações e acréscimos de valores, formas de pensamento, técnicas, normas religiosas, morais e jurídicas, entre unidades históricas que mantém contatos ou que se relacionam por um nexo de filiação, como o que existe entre a nossa cultura ocidental e a cultura helênica.

Segundo Nunes (2004), as três acepções do conceito de cultura não se opõem entre si, compõem as três escalas ou os três aspectos de uma só idéia, segundo as quais, a cultura do indivíduo está em relação com a da sociedade, e da sociedade, por sua vez, equivalendo a uma forma historicamente evoluída, está definida no conjunto de um processo global de que o gênero humano é o último usufrutuário.

Para Geertz (1989), o conceito de cultura teve algumas concepções ao longo do tempo, que foram definidas como: concepção estratigráfica, concepção do padrão universal e concepção sintética. A concepção estratigráfica é onde se observa as relações entre os fatores biológico, psicológico, social e cultural. Surge a tentativa de localizar o homem no conjunto dos seus costumes. De acordo com essa concepção, o homem é um composto de níveis, cada um superposto aos inferiores. Quando se analisa o homem, retira-se camada após camada, sendo cada uma delas completas e irredutíveis em si mesma. Retiram-se os fatores psicológicos e surgem os fundamentos biológicos de todo edifício da vida humana.

Na concepção do padrão cultural universal, chamada também de "denominadores comuns da cultura", acreditava-se que se poderia encontrar nas particularidades culturais de um povo, algo em comum a todos, universal, onde a diversidade de costumes no mundo e no tempo podia ser encontrada em todo lugar e praticamente da mesma forma. Dessa maneira, a antropologia podia determinar as dimensões culturais coincidentes com a dimensão biológica, psicológica e sociológica. Essa procura pelo universal, Geertz (1989, p. 51) chamou de "consensus gentium" (um consenso de toda a humanidade).

O autor, no entanto, critica a generalização dessa teoria, pois acredita que não seja possível sustentá-la. O problema da generalização está na integração dos processos biológicos, psicológicos ou sociológicos. Como isso pode ser possível se esses são níveis científicos separados e autônomos em si mesmo? O refúgio no universal pelos antropólogos, 
diante de tanta diversidade, é o medo de se perderem no relativismo cultural, que os privará de um ponto fixo.

A cultura é vista conceitualmente mais poderosa quando limitada, mais específica. A análise particular, a redução do conceito de cultura, que é uma dimensão justa. Com a especificação é possível descrições minuciosas, não generalizações de casos específicos (da parte ao todo), mas generalizar dentro desses casos. O objetivo é tirar grandes conclusões de fatos pequenos, densamente entrelaçados.

A concepção sintética é uma substituição a concepção estratigráfica, na qual os fatores biológicos, psicológicos, sociológicos e culturais possam ser tratados como variáveis, dentro dos sistemas unitários de análise.

Para Loureiro (1992) a cultura pode ser representada em dois grandes grupos: a cultura erudita e a cultura popular. A cultura erudita, como é produzida pela alta classe média e a classe alta, contém um maior grau de informação e incorporação do patrimônio representado pela cultura ocidental, no qual inúmeros aparatos, tais como meios de comunicação, revistas, jornais, Internet etc., têm no seu bojo, um maior acesso aos diversos tipos de informações, o que lhe dá um aspecto que Loureiro (1992, p. 178) denomina de "erudição" ou "expressão erudita".

Já a cultura popular é a expressão de uma camada da população que tem menos acesso aos bens culturais da tradição erudita e exprime mais uma relação direta com a vida, fundamentando-se no que essas pessoas veem, sentem e ouvem acerca das coisas que estão à sua volta, por meio do pragmatismo cotidiano. No entanto, hoje, esse cenário sobre cultura popular está mudando. A perspectiva de que a cultura popular tem menos acesso aos bens culturais da cultura erudita é verdade, mas, embora não ocorra na mesma proporção e na mesma velocidade, em função das tecnologias de informação e da chamada "globalização", muitos bens culturais tem alcançado as camadas mais baixas e regiões mais longínquas e de pouco desenvolvimento.

Neste tópico, foram apresentadas algumas escolas de pensamento sobre o conceito de cultura, cujo intuito era mostrar sua complexidade, a partir das múltiplas maneiras de olhar para a mesma. Percebe-se que, ainda hoje, os antropólogos e sociólogos não dispõem de um consenso sobre o conceito. Esses pontos de vista acerca da cultura, aliado com os contatos interétnicos, trocas de bens culturais e informações oriundas da facilidade gerada pelas tecnologias de informação, o domínio de conhecimento cultura torna-se um grande desafio para a construção de um sistema de organização do conhecimento. O desafio pode refletir desde as etapas iniciais, como a seleção elementos conceituais do sistema, a categorização, a formação de renques e cadeias no interior do sistema até a sua manutenção e capacidade de hospitalidade contínua, princípio estabelecido por Ranganathan (1967).

\section{Seleção conceitual e o dinamismo do conhecimento}


Todo conhecimento é dinâmico, está sempre evoluindo, refletindo, assim, nos instrumentos de organização de conhecimento, na delimitação de seus limites e na seleção conceitual. Nas ciências humanas e sociais não é diferente. Quando se tem como referencial a sociedade, a cultura, o dinamismo também é acentuado, tendo em vista o movimento contínuo que ocorre a partir das trocas de informações com o ambiente externo e o próprio ambiente interno. Os contatos interétnicos, as colonizações, os grandes momentos históricos de impacto cultural forte e, hoje, a globalização, os meios de comunicação de massa, como a televisão, as novas TICs e a Internet etc., fazem com que o movimento de fora para dentro em uma dada cultura seja intenso e constante, variando apenas nas formas e nos objetivos.

As influências externas produzem, no interior de uma sociedade, movimentos e impactos culturais que abalam sua condição vigente. No Brasil, por exemplo, antes de 1500, viviam apenas índios com suas visões de mundo, seu sistema de linguagem, sua mitologia, suas formas de pensar o mundo e sua religião. Com a chegada do europeu e depois do negro africano, e de muitos outros, mais tarde, alterou-se seu cenário cultural. Quando os conquistadores determinaram que o tupi fosse a língua geral brasileira, sabendo-se que haviam mais de mil línguas indígenas existentes, muitas línguas foram extintas com seu povo, assim como muitos mitos se extinguiram com sua língua (GAMBINI, 2002).

Quando se trabalha com domínios de conhecimentos específicos, a seleção inadequada dos conceitos pode refletir na qualidade da sua recuperação da informação. Essa seleção depende se a terminologia é consistente em uma dada área. Smit, Tálamo e Kobashi (2004) apontam que o vazio conceitual de um campo científico e a imprecisão terminológica provocam um retardamento teórico para a área. A autonomização da linguagem de especialidade, afastando-a da linguagem natural, constitui um pressuposto para a constituição de qualquer campo científico.

Bowker e Star (2000) comentam que para a entrada de novos conceitos no sistema é necessário que os mesmos tenham um consenso na área pela comunidade científica, e se o sistema não estiver atento para a atualização dos novos conceitos que surgem, a defasagem pode afetar a recuperação da informação e causar sérios problemas para o sistema.

A área da cultura, estudada há muitos anos por antropólogos, sociólogos, filósofos, psicólogos, comunicólogos, historiadores, geógrafos e outros, não se pode dizer que é um campo imaturo cientificamente. Contudo, como é um conceito ligado ao todo e não ao indivíduo e como àqueles, os homens, que a estudam, são partes desse todo, o conceito se torna muito complexo ao ponto dos estudiosos considerarem cultura como um dos conceitos mais difíceis de definir.

Como alguns dos conceitos ligados ao campo da cultura, começando pelo seu próprio conceito, não são de comum consenso entre os estudiosos da área, a seleção e relação conceitual em um sistema de organização do conhecimento, cujo domínio envolve o conceito de cultura, 
ficam prejudicadas. É necessário ter uma clara definição do que é o conceito de cultura para saber quais elementos devem compor esse conjunto. Como não há consenso, é relevante entender as várias escolas originárias, ao longo do tempo, em que são estudados o conceito, e determinar qual será seguida para construção do sistema.

Os problemas do consenso e da complexidade do conceito cultura também decorrem das problemáticas inerentes da própria natureza das ciências sociais e humanas. Como alguns de seus objetos de estudo, como o homem e a sociedade, não são elementos tão factuais e verificáveis claramente como podem ser, por exemplo, os elementos químicos, a gravidade, a velocidade, o vírus, a planta, formam-se várias escolas de pensamento compondo um conjunto de ideias, muitas vezes contrárias entre si, a respeito do conceito. Essas várias maneiras de olhar o conceito vão refletir na delimitação do universo de um domínio de conhecimento e nas relações entre seus conceitos.

A seleção conceitual de um dado domínio de conhecimento também se torna complexa porque o conhecimento é dinâmico e progressivo. Muitos estudiosos e filósofos, como Ranganathan, acreditam que o conhecimento se desenvolve tal como um espiral cíclico, contínuo e infinito. Esse dinamismo vai refletir nas estantes das bibliotecas e implicará na construção de um sistema de organização do conhecimento. Por isso, Kumar (1986) adverte que as descobertas do plano das ideias, onde são encontrados os conceitos, devem ser seguidas e postas em prática no plano notacional, plano que serve para fixação abstrata dos conceitos para possibilitar uma sequência útil nas estantes. As descobertas que ocorrem no plano das ideias, os novos conceitos que surgem, devem ser trabalhados na seleção conceitual, mesmo depois de construído o sistema, sendo necessário, portanto, que apresente uma estrutura capaz de receber esses novos conceitos.

Pensando no dinamismo do conhecimento, Ranganathan (1967 apud CAMPOS, 2001), ao elaborar o Postulado das Ideias Fundamentais, alerta todos os classificacionistas a estarem atentos para a hospitalidade contínua de novos elementos. Para explicar o movimento que ocorre no Universo do Conhecimento e sua influência sobre os esquemas de classificações, apresenta o Espiral do Universo do Conhecimento, utilizando os pontos cardeais para mostrar suas várias fases: Nadir, Ascendente, Zênite e Descendente. Entre essas fases, o método científico é dado a verificar empiricamente a validade das novas leis, através das observações e dos experimentos. Nesse momento, ocorre a incidência da crise na aplicação do método científico, assim um novo ciclo se inicia infinitamente.

Entendendo o dinamismo do conhecimento, Ranganathan (1967 apud CAMPOS, 2001) sugere a Árvore Baniana, para representar a organização do conhecimento em contraponto à Árvore de Porfírio, de Aristóteles.

A árvore de Porfírio compõe-se por dicotomias sucessivas, que procedem do geral ao particular, da maior extensão à maior compreensão, 
do gênero à species ínfima, ou seja, até chegar a um conceito individual. A partir do século $X X$, percebeu que o método baseado na representação da Árvore de Porfírio, segundo Campos e Gomes (2003), falha porque os assuntos dos documentos não fazem parte de um único domínio de conhecimento, pelo contrário, eles são complexos e se inter-relacionam.

A árvore baniana sugere uma analogia em que o conhecimento é inter-relacionado e as disciplinas se cruzam infinitamente. Ela se contrapõe à Árvore de Porfírio, dicotômica, e propõe uma policotomia ilimitada. Por isso, para Campos e Gomes (2003), a analogia com a árvore baniana é muito mais apropriada para a representação do conhecimento atual, cuja produção da informação é extraordinariamente ilimitada.

O domínio cultura se enquadra melhor ao método da policotomia ilimitada. Primeiro pelo ponto de vista da interdisciplinaridade, em que vários olhares são fornecidos pelos inúmeros campos do conhecimento que estudam o conceito de cultura. E, depois, porque a inter-relação entre os elementos do sistema cultural é inerente a própria cultura. Existe um todo (cultura) que se relaciona com suas partes (fauna, flora, religião, mitologia, formas de pensar a vida e a natureza etc.).

A ideia de interconexão e integração entre os elementos do todo corrobora tanto com a Teoria de Ranganathan quanto com a Teoria dos Níveis Integrativos, do Classification Research Group.

Toda cultura é dinâmica pelo movimento da sua própria evolução e pelas trocas e imposições culturais, consequência de momentos históricos importantes. A questão então que se apresenta é: como delimitar a extensão de um domínio de conhecimento dividido por uma tênue camada?

Como delimitá-la, em sua profundidade, certamente não é obra deste trabalho, porque cultura é um conceito complexo, mas o que pretendemos é discutí-la do ponto de vista da seleção conceitual em um instrumento de organização de domínios de conhecimento, a partir de abordagens teóricas, que lidam com domínios complexos, como a teoria de Ranganathan e a Teoria dos Níveis Integrativos do CRG.

O que é importante observar na construção de um sistema de domínio, dessa natureza, são as várias escolas de pensamentos que existem sobre o conceito e escolher uma que seja mais adequada ao propósito da classificação, saber o propósito pelo qual o sistema está sendo criado, qual perfil de seus usuários e escolher a estrutura de classificação com bases teóricas bem fundamentadas.

\section{O domínio da cultura nas etimologias das palavras}

Para evidenciar a diversidade cultural do domínio de conhecimento cultura e mostrar a complexidade do conceito para construção de sistemas de organização do conhecimento, foram escolhidas as etimologias dos termos do universo cultura amazônica e a influência das etimologias nãonativas na sua língua. Como ilustração, produzimos um quadro das 
etimologias obtidas em Oliveira (2005a; 2005b; 2010) dos termos culturais da região amazônica paraense.

Foram usados os termos amazônicos, primeiramente porque é parte da pesquisa que estamos desenvolvendo no mestrado e, segundo, porque os termos foram coletados por Oliveira nos interiores paraenses, onde se supõe existir uma raiz indígena forte, levando-nos a pensar nas raízes da identidade cultural brasileira, antes do contato interétnico com civilizações de outros continentes. Assim, conseguimos pensar como as línguas de outros continentes se agregaram à língua brasileira que, antes da "chegada do europeu no século XIV", em terras brasileiras, que eram habitadas somente pelos índios.

A TAB. 1, abaixo, mostra os resultados das origens etimológicas dos termos culturais amazônicos dos municípios paraenses Bragança, Castanhal e arquipélago do Marajó, disponíveis em Oliveira (2005a; 2005b; 2010).

TABELA 1 - Total de termos das origens etimológicas dos municípios de Bragança, Castanhal e Marajó

\begin{tabular}{lll}
\hline \multicolumn{3}{c}{ CIDADES: BRAGANÇA, CASTANHAL E } \\
\multicolumn{3}{c}{ MARAJÓ } \\
\hline Origem etimológica & Termos & $\begin{array}{l}\text { Percentual } \\
(\%)\end{array}$ \\
Africano & 1 & 0,1 \\
Árabe & 12 & 1,4 \\
Castelhano & 3 & 0,3 \\
Catalão & 3 & 0,3 \\
Celta & 2 & 0,2 \\
Chinês & 1 & 0,1 \\
Espanhol & 50 & 6,0 \\
\hline Francês & 46 & 5,5 \\
Germânica & 5 & 0,6 \\
\hline Gótico & 15 & 1,8 \\
Grego & 16 & 1,9 \\
Inglês & 1 & 0,1 \\
loruba & 1 & 0,1 \\
Italiano & 12 & 1,4 \\
\hline Latim & 517 & 62,2 \\
Malaio & 5 & 0,6 \\
\hline Origem & 16 & 1,9 \\
Onomatopaica & & \\
\hline Portuguesa & 2 & 0,2 \\
\hline Quicongo & 2 & 0,2 \\
\hline Quimbundo & 7 & 0,8 \\
\hline Tâmul/Malaiala & 2 & 0,2 \\
\hline Tupi & 111 & 13,3 \\
Tupi-guarani & 1 & 0,1 \\
TOTAL & 831 & 100 \\
\hline Fonte: Dados & & \\
\hline
\end{tabular}

Fonte: Dados da pesquisa.

Analisando os termos da tabela acima (TAB. 1), observa-se a presença predominante da etimologia latim. A presença do tupi, do francês e do espanhol também é significativa em relação às demais. É possível identificar a variedade etimológica na linguagem amazônica. 
Do total de termos analisados, podemos observar as origens etimológicas das línguas por continentes, conforme o gráfico 1, abaixo. A maior parcela de etimologias foi representada pelas línguas européias, em segundo lugar a América, em seguida Ásia e África. A influência européia muito se deve em função da influência do latim, do espanhol e do francês, assim como no caso da América se deve à língua tupi.

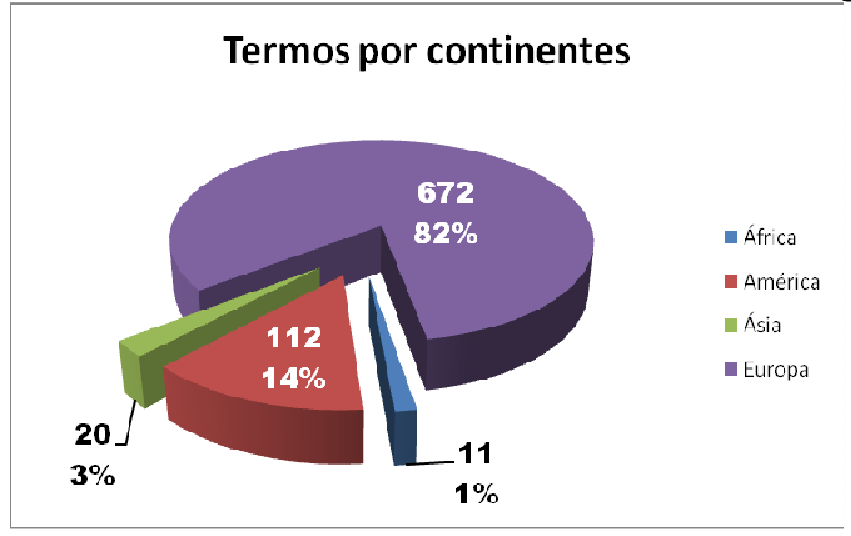

GRÁFICO 1 - Etimologias amazônicas por continente

Fonte: Dados da pesquisa.

Das etimologias que apareceram nos termos culturais amazônicos, 672 termos (82\%) têm origem na Europa, são eles: castelhano; catalão; celta; espanhol; francês; germânica; gótico; grego; inglês; italiano; latim; e português. Onze termos (1\%) são de origem etimológica do continente africano: africano; iorubá; quicongo; quimbundo. Vinte termos (3\%) do continente asiático: árabe; chinês; malaio; e tâmul/malaiala. $\mathrm{E}$, cento e doze termos (14\%) dos povos indígenas brasileiros (América): tupi; e tupi-guarani.

A influência da língua europeia na língua brasileira, em especial na linguagem amazônica, deve-se à colonização da Europa no Brasil, desde as grandes navegações do século XVI.

A grande influência do latim na língua brasileira deve-se a dois motivos. O primeiro é que o português, chamada de língua neolatina, é uma variação e tem no latim sua língua ancestral. A partir da chegada dos portugueses nas terras brasileiras, no século XVI, a língua dos dominadores torna-se muito influente, agregando-se com a língua indígena tupi. Dessa mistura de língua europeia e indígena, forma-se o português do Brasil, que tem em sua estrutura algumas diferenças em relação ao português de Portugal.

O segundo motivo que podemos pressupor é que com a missão dos padres jesuítas de catequizar os nativos indígenas, o latim teve grande influência no território brasileiro. O latim foi a língua do Império Romano e é, ainda hoje, a língua oficial da Igreja Católica, que pode ter sido usada na leitura e ensino da Bíblia.

Para Gambini (2000, p.174), antes da chegada do europeu, talvez existissem mais ou menos mil línguas indígenas e hoje só restaram 170 . A grande influência do latim e a determinação do tupi como língua oficial do 
Brasil fizeram com que muitas línguas nativas fossem extintas, já que houve, nas palavras do autor, um terrível processo de destruição cultural e humana no Brasil. "Por meio da catequese, a cruz de Cristo é uma espada cravada no peito indígena para matar sua alma". Muitas formas de pensar o mundo do nativo indígena estavam presentes na sua mitologia, como inconsciente coletivo. Muitos mitos foram extintos ao longo do tempo, com o desaparecimento do seu povo e de sua língua, já que essas sociedades eram ágrafas.

Veríssimo (1970) comenta que o português de Portugal e o português brasileiro são diferentes em função da língua indígena tupiguarani. Muitos nomes da fauna, flora e certos utensílios, foram corrompidos pelos portugueses. Essa fusão de línguas teve reflexos tanto para a linguagem de Portugal quanto para a brasileira. Mesmo com essa troca mútua, podemos observar, pela tabela acima, a dominação do conquistador diante do conquistado, através da sobreposição das línguas não-nativas em relação ao tupi, especialmente o latim trazido pelos europeus e jesuítas missionários.

A influência das etimologias de origem africana apresenta um total de 11 termos (1\%). As palavras de origem etimológica africana, embora nossa expectativa fosse maior, não se mostraram muito representativas. É provável que a influência das línguas africanas tenha causado mais impacto em outros pontos do Brasil, como nos estados do Rio de Janeiro, Maranhão e Bahia, pois os chamados navios negreiros transportavam escravos negros principalmente para as cidades de Rio de Janeiro, Salvador, Recife e Bahia.

No Brasil, de uma forma geral, a influência da língua africana devese à vinda de escravos trazidos forçadamente pelos europeus, para suprir mão de obra. A maior parte dos escravos africanos provinha da Angola, Guiné, Benin, Nigéria e Moçambique. Seu início ocorreu na segunda metade do século XVI, até ser extinta em 1850. O tráfico negreiro foi uma atividade altamente lucrativa, que pagava impostos tanto para a Igreja Católica (dízimo) quanto para a Coroa Portuguesa.

As línguas tâmul/malaia e 0 árabe são línguas faladas pelos asiáticos, assim como também pelos africanos. O que nos leva a pensar que certamente a sua influência, pelo menos na Amazônia, devem ter sido trazidas pelos africanos escravos advindos do continente africano, tendo em vista que a cultura africana foi mais significativa do que a asiática na região.

Já o chinês e o malaio, palavras de origem etimológica asiática, somaram um total de 20 termos, representando $3 \%$ do total, considerando a classificação por continentes. A influência dos asiáticos deve-se à sua imigração para o Brasil para trabalhos, principalmente na agricultura. Os chineses foram trazidos com o objetivo de introduzir o cultivo de chá no Brasil. Houve também os imigrantes japoneses que, na primeira metade do século $X X$, vieram trabalhar nos cafezais de São Paulo. 
As palavras de origem onomatopéica somaram 16 termos $(1,9 \%)$, mas não constituem um valor significativo para este trabalho. Como pretendemos evidenciar a diversidade cultural, a partir das etimologias das palavras amazônicas, a onomatopéia não apresenta essa informação. Onomatopéia é uma figura de linguagem, na qual se reproduz um som com um fonema ou palavra, é a imitação de um som, mas não tem uma origem etimológica relacionada a alguma língua.

Pelos resultados revelados nos números acima, pode se reiterar a complexidade do domínio cultura. Através da análise das origens etimológicas, foi mostrada a influência das línguas de várias partes do mundo na língua brasileira, sendo que concentramos o estudo na etimologia da terminologia cultural amazônica. É válido ressaltar que esses termos foram coletados por Oliveira (2005a; 2005b; 2010), a partir de narrativas orais dos moradores dos municípios dos interiores paraenses, teoricamente uma região mais ligada às tradições indígenas e com menos contatos interétnicos, em relação às grandes cidades brasileiras.

O resultado dessa pesquisa etimológica demonstra que a cultura brasileira é tomada por um hibridismo cultural e uma mestiçagem muito forte. Ressalta-se que as etimologias que se revelaram na linguagem amazônica são reflexos históricos das migrações de diversos povos, consequência de políticas internacionais inicialmente, e, depois, pelas políticas nacionais na região amazônica, como na Era da Borracha, Política de Integração Nacional, nos anos 60 do século $X X$, e, ainda, os grandes projetos que ocorreram na Amazônia, entre outros.

\section{Teorias que fundamentam a elaboração de sistemas de organização do conhecimento em domínios complexos e interdisciplinares}

O intuito deste trabalho não é esgotar todas as teorias que podem auxiliar na construção de um sistema de organização de conhecimento, mas comentar sobre duas que são potencialmente pertinentes para se trabalhar em domínios complexos, como o domínio cultura, que são: a Teoria da Classificação Facetada, de Ranganathan e a Teoria dos Níveis Integrativos, pela abordagem do Classification Research Group.

A Teoria da Classificação Facetada foi desenvolvida por Shiyali R. Ranganathan, na década de 30. Ranganathan, por influência dos estudos biblioteconômicos, da sua formação acadêmica em matemática, analisou como ocorre o fluxo do conhecimento e como isso poderia refletir nas estantes das bibliotecas. Impulsionado pela sua pesquisa intensiva, elaborou a Colon Classification, também denominada de Classificação de Dois Pontos. Embora esse esquema de classificação não seja muito utilizado nas bibliotecas de todo o mundo, sua teoria, fundamentos e princípios, revolucionaram a forma de pensar a classificação.

Para Schreiner (1979), a Colon Classification é algo totalmente novo para a classificação bibliográfica. Baseia-se no princípio analítico-sintético, 
em oposição ao hierárquico-enumerativo. Seu sistema foi desenvolvido a partir do prisma do dinamismo do conhecimento, dando a possibilidade do conhecimento ser estruturado de maneira que os assuntos compostos sinteticamente surgissem a partir de conceitos elementares.

Ranganathan (1967) chama a atenção que ao serem elaborados sistemas de classificação deve-se atentar para as mudanças e a evolução do conhecimento. Em seu Postulado das Ideias Fundamentais, alerta todos os classificacionistas a estarem atentos para a hospitalidade contínua de novos elementos, posto que o conhecimento humano é dinâmico. Ele discute a formação dos conceitos, através dos perceptos puros e compostos ${ }^{1}$ e a relação com o que chamou de Universo das Ideias ou do Conhecimento e os trabalhos de classificação.

Para explicar o movimento que ocorre no Universo do Conhecimento e sua influência sobre os esquemas de classificações, Ranganathan apresenta o Espiral do Universo do Conhecimento, utilizando os pontos cardeais para mostrar suas várias fases: Nadir (fatos obtidos pela observação, experimentação e outras formas de experiência), Ascendente (leis indutivas ou empíricas em referência aos fatos acumulados em Nadir), Zênite (leis formuladas, a compreensão de todas as leis indutivas ou empíricas acumuladas no Ascendente com implicações obrigatórias) e Descendente (acumulação das leis de dedução na direção das leis fundamentais de Zênite) (CAMPOS, 2001).

Entre essas fases, o método científico é dado a verificar empiricamente a validade das novas leis, através das observações e dos experimentos. Nesse momento, ocorre a incidência da crise na aplicação do método científico, assim um novo ciclo se inicia infinitamente.

No Postulado das Categorias, Ranganathan (1967 apud CAMPOS, 2001) preocupou-se com a concepção de categorias fundamentais. Esse postulado é um princípio normativo que serve para organizar um Universo/Domínio. As categorias fundamentais são o primeiro recorte feito no universo ou domínio do conhecimento. Para Ranganathan existem cinco categorias fundamentais, que podem dividir todo e qualquer assunto, são elas: Personalidade, Matéria, Energia, Espaço e Tempo (PMEST). Entretanto, outras categorias fundamentais podem ser criadas na construção de um sistema de organização do conhecimento.

Um método que pode auxiliar a seleção conceitual na elaboração de uma estrutura classificatória é a categorização. A categorização permite uma análise conceitual de um domínio possibilitando um recorte amplo e permitindo um caminho inicial de divisão, como é o caso do PMEST. Para Campos e Gomes (2006), consiste em identificar as possíveis classes

\footnotetext{
${ }^{1}$ Percepto puro é a impressão produzida por uma entidade através de um sentido primário simples e percepto composto é a associação de dois ou mais perceptos puros formados simultaneamente. $\mathrm{Na}$ medida em que os perceptos puros e compostos são depositados na memória de uma entidade, dáse a associação e formam-se os conceitos. Após o ser humano criar uma identidade com o mundo que o cerca, pelo processo de aglutinação e associação dos perceptos, em um momento posterior à formação dos conceitos, ocorre a assimilação de novas experiências, o que leva ao que Ranganathan denominou de apercepção (CAMPOS, 2001).
} 
gerais (categorias) de conceitos que a área do conhecimento comporta. Essa etapa estabelece as bases para seleção dos termos, nas fontes de onde eles são coletados. A categorização é descrita por Campos e Gomes (2008, p. 4), como:

um processo que requer pensar um domínio de forma dedutiva, ou seja, determinar as classes de maior abrangência dentro da temática escolhida. Na verdade, aplicar a categorização é analisar o domínio a partir de recortes conceituais que permitem determinar a identidade dos conceitos (categorias) que fazem parte desse domínio.

A Teoria da Classificação Facetada pode ser útil a domínios complexos, como a cultura, pela visão dinâmica do conhecimento. Reflexo dessa forma de pensar, representado pela Árvore Baniana e pela idéia da policotomia ilimitada, Ranganathan propõe o método facetado em que torna possível no sistema uma flexibilidade, um inter-relacionamento mútuo entre seus elementos.

Outra teoria que pode ajudar na construção de sistemas de organização do conhecimento em domínio cultural é a Teoria dos Níveis Integrativos. Não se tem uma origem precisa sobre a teoria, mas pode-se dizer que a raiz dessa concepção pode ser encontrada nos cinco níveis de Aristóteles. No século XIX, a teoria recebeu grande impulso com a filosofia positivista de Augusto Comte, que acreditava que a classificação das ciências existia na ordem do mais simples para o mais complexo e as mais complexas dependiam das mais abstratas (SPITERI, 1995).

Para os estudos da teoria da classificação, o Classification Research Group (CRG) adotou como base a teoria de Ranganathan e a Teoria dos Níveis Integrativos. O CRG tem realizado contribuições significativas para a teoria da classificação.

Nas origens do CRG, o grupo foi formado para estudar a natureza da classificação e os sistemas de classificação bibliográfica existentes. Ao analisar tais instrumentos, todos os membros do grupo rejeitaram todos os esquemas de classificação tradicionais, como a CDD e a CDU, tidos como insuficientes para a documentação moderna.

O CRG opôs-se aos sistemas tradicionais, porque o universo do conhecimento não poderia ser definido como finito e, ainda, subdividido até os conceitos individuais. Desse modo, o CRG, tomando como base a Teoria dos Níveis Integrativos, sugeriu uma abordagem bottom-up, em contraposição a abordagem top-down dos sistemas tradicionais. Questionou, em vez de quebrar o universo do conhecimento em classes, e analisar essas classes até se chegar a conceitos individuais, sugeriu que os conceitos formassem assuntos.

O CRG interpretou a Teoria dos Níveis Integrativos da seguinte forma: o mundo das coisas se desenvolve do simples para o complexo pelo acúmulo das propriedades novas e divergentes. De coisas simples evoluem coisas complexas e de coisas complexas evoluem coisas mais complexas (NOVO, 2007). 
Para a Teoria dos Níveis Integrativos considera-se a evolução do desenvolvimento das entidades, com base na estrutura de seus componentes internos. Para Schreiner (1979), o conceito de níveis integrativos de organização é a descrição geral da evolução da matéria, através das sucessivas e mais altas ordens de complexidade e integração. O desenvolvimento da matéria é visto desde as mudanças cosmológicas, que resultam na formação da Terra, até as mudanças sociais complexas de uma sociedade por um processo contínuo, passando por diferentes níveis de organização, como o físico, o químico, o biológico e 0 sociológico.

Cada entidade preserva sua integridade nas relações com suas partes. Como a entidade evolui do simples para o mais complexo pela acumulação de propriedades ou influências do ambiente, a relação entre a entidade e o ambiente fica mais complexa. Com o tempo, ocorrem agregações de entidades ou propriedades e forma-se um novo todo mais complexo. A nova entidade tem propriedades próprias e se comporta de maneira nova. Cada entidade inteira é maior que a soma das partes, se uma das relações estiver quebrada, a entidade perde sua identidade (FOSKETT, 1978). Nessa perspectiva, a noção de "integração" é inseparável da noção de "totalidade", porque o todo é composto de uma série de elementos integrados.

Para Gnoli, Bosh e Mazzocchi (2007) a pesquisa multidisciplinar aumentou muito nos últimos tempos, sendo necessária uma mudança de paradigma para construir novos sistemas de classificação mais flexíveis e hospitaleiros. O CRG foi um dos primeiros a perceber que os sistemas tradicionais não eram mais suficientes para a documentação moderna.

Para Costa e Ramos (2008), o CRG não considera que as categorias fundamentais de Ranganathan (PMEST) sejam as melhores a serem aplicadas a qualquer campo do conhecimento e, portanto, devem deixar de ser fundamentais e passar a ser escolhida de acordo com o campo de assunto, portanto, reformularam o PMEST e criaram categorias mais pragmáticas.

Uma das preocupações do CRG era como poderia ser ordenados os conceitos dentro das categorias. Propôs no princípio da ordem nos renques a seguinte ordem de assuntos: simples para o complexo; complexo para o simples; espacial/geométrico; cronológico (incluindo as ordens evolucionária e histórica); e a alfabética (LIMA 2004). E sugeriu que as categorias fossem organizadas pelas seguintes classes:
a)entidades físicas;
b)entidades químicas;
c)entidades heterogêneas não-vivas;
d)artefatos;
e)entidades biológicas;
f)homens; e
g)mentefatos. 
Para Spiteri (1995), essas classes resultaram em críticas porque não seguiam a ordem de consistência da Teoria dos Níveis Integrativos. Por que Artefatos precedem a classe Homens se artefatos são feitos e dependem dos homens para sua existência? O CRG não explica claramente se esta proposta de classes pode ser usada para qualquer ordem sistemática.

Spiteri (1995) afirma que a aplicação da Teoria dos Níveis Integrativos pelo CRG tem gerados muitos problemas e tem produzido mais perguntas do que respostas. Na aplicação da teoria nos sistemas de classificação especializados, o CRG observou que os níveis integrativos não envolveram uma progressão linear ascendente, mas uma ramificação. Perceberam que formaram uma estrutura de ramificação em vez de uma única sucessão. Um nível integrativo pode formar dois ou mais campos e subdividir ainda mais. O resultado disso é que a teoria não pode ser usada para formar uma única seqüência de classes, como esperavam.

Pensando na Ciência da Informação como uma área interdisciplinar, Wilson (2002) comenta que a informação é um conceito que assume diferentes formas em diferentes níveis de integração. Pode ser olhado pela ciência da computação, pelos bibliotecários, pelos especialistas de recuperação da informação, entre outros. Assim como a informação, o conceito de cultura também assume diferentes níveis de integração e pode ser apreendido por diversas maneiras, como os aspectos observados pelos estudiosos da Antropologia, Sociologia, História, Comunicação Social, Geografia, Filosofia e outros e as várias escolas de pensamentos sobre cultura.

Os vários olhares possíveis do domínio cultura refletem na construção do sistema de organização do conhecimento. Para Novo (2010), os estudiosos preocupados com o problema da classificação de domínios de conhecimento são unânimes em afirmar a existência de vários pontos de vistas no ato classificatório. A decisão da melhor forma de recortar um dado domínio depende do seu propósito.

O pensar sistêmico e integrado da organização do conhecimento na Teoria dos Níveis Integrativos é um pensamento pertinente ao domínio de conhecimento cultura. Na Teoria dos Níveis Integrativos os conceitos não podem ser compreendidos isoladamente, mas de forma interconectada dependente de processos cíclicos. Para Novo (2010), como o foco da teoria é a interconectividade, ela ajuda a lidar com estruturas complexas dos conceitos, que podem ser usadas em qualquer área.

Sendo a cultura um todo delimitado geograficamente, composta por partes como indivíduos, artefatos produzidos pelos mesmos, a natureza e a forma de pensar, mesmo heterogênea está determinada por padrões culturais, então, nesse domínio do conhecimento devem ser pensados seus conceitos de forma integrativa. A cultura é um todo complexo que revela sua identidade nas relações de suas partes, nas relações sociais, nas relações biológicas, nas relações entre homem e natureza, ou seja, nas relações integrativas de seus elementos. 
Para Novo (2007, p. 111), a Teoria dos Níveis Integrativos, como o próprio nome já diz, é uma teoria e não fornece um método classificatório, mas ela permite olhar um domínio complexo, como a cultura, nas suas questões fundamentais de maneira mais clara, a partir de diferentes perspectivas disciplinares. "Apresenta princípios e não uma dada forma do fazer."

\section{Considerações finais}

Os objetos de estudo das ciências sociais e humanas são complexos, pois quem os estuda é o próprio homem, parte do todo estudado. Sendo seu objeto complexo, a seleção conceitual na construção de um sistema de organização do conhecimento também se torna uma atividade difícil, comprometendo a recuperação e a indexação adequada.

A diversidade cultural que foi revelada nas análises das etimologias e as escolas de pensamento sobre o conceito de cultura são dois aspectos que evidenciam a complexidade do domínio. Quanto mais híbrida e múltipla for uma sociedade, mais complexa se torna a seleção conceitual de um sistema de organização do conhecimento, pois seus limites são mais tênues.

Mesmo a cultura sendo um conceito complexo, decorrência dos contatos interétnicos em momentos importantes da história de uma civilização, das modificações internas que ocorrem, a partir de uma invenção ou de algum acontecimento importante, das trocas de bens culturais com outras culturas, em cada sociedade existe o que Braudel (2004) chamou de estrutura cultural. Essas estruturas são as raízes mais profundas de uma civilização e se alteram muito lentamente porque é, consciente ou inconscientemente, o seu alicerce.

Desse modo, dependendo do propósito da classificação, ao se pensar na construção de sistemas de organização do conhecimento no domínio cultural, é necessário focar nessas originalidades e raízes profundas, além de buscar o que depois foi se agregando junto a essa estrutura sólida. As ideias de Braudel (2004) revelam, então, uma diretriz teórico-metodológica em sistemas de domínios culturais, mostrando a possibilidade de realização mais sólida da seleção conceitual.

A Teoria da Classificação Facetada, seus cânones, o método policotômico ilimitado, o método facetado e a possibilidade de construir um sistema flexível para receber elementos novos (hospitalidade contínua) ajudam a suportar o dinamismo do conhecimento e trabalhar domínios complexos. Assim como a Teoria dos Níveis Integrativos, através do pensamento integrativo e interconectado, da evolução do simples ao complexo das coisas auxilia a pensar domínios de natureza complexa e interdisciplinar, como a cultura e as ciências humanas e sociais.

\section{Referências}


BOWKER, G. C.; STAR, S. L. Sorting things out: classification and its consequences. Cambridge, Massachussetts: MIT Press, 2000. cap. 3. p. 107-161.

BRAUDEL, F. Gramática das civilizações. 3 ed. São Paulo: Martins Fontes, 2004.

CAMPOS, M. L. A. A organização de unidades de conhecimento em hiperdocumentos: o modelo conceitual com um espaço comunicacional para realização da autoria. 2001. 171 f. Tese (Doutorado em Ciência da Informação). Escola de Comunicação da Universidade Federal do Rio de Janeiro, Rio de Janeiro, 2001.

CAMPOS, M. L. A.; GOMES, H. E. Organização de domínios de conhecimento e os princípios ranganathianos. Perspectiva em Ciência da Informação, Belo Horizonte, v. 8, n. 2, p. 150-163, 2003.

- Metodologia de elaboração de tesauro conceitual: a categorização como princípio norteador. Perspectiva em Ciência da Informação, Belo Horizonte, v. 11, n. 3, p. 348-359, 2006.

- Taxonomia e classificação: o princípio de categorização. DataGramaZero: Revista de Ciência da Informação, Rio de Janeiro, v. 9, n. 4, p. 1-13, ago. 2008.

COSTA, F. C.; RAMOS, L. B. Análise facetada: em busca de uma classificação para o teatro. Ponto de Acesso, Salvador, v. 2, n. 3, p. 3042, dez. 2008. Disponível em: <http:www.pontodeacesso.ici.ufba.br>. Acesso em: 22 dez. 2010.

EAGLETON, T. A idéia de cultura. São Paulo: UNESP, 2005.

FOSKETT, D. J. The theory of integrative levels and its relevance to the design of information systems. Aslib Proceedings, v. 30, n. 6, p. 202-208, 1978.

GAMBINI, R. Espelho de índio: a formação da alma brasileira. 2. ed. São Paulo: Axis Mundi/Terceiro Mundo Nome, 2000.

GEERTZ, C. A interpretação das culturas. Rio de Janeiro: Livros Técnicos e Científicos, 1989.

GNOLI, C.; BOSH, M.; MAZZOCCHI, F. A new relationship for multidisciplinary knowledge organization systems: dependence. In: BRAVO, B. R.; ALVITE DÍEZ, M. L. (Orgs.). INTERNATIONAL SOCIETY KNOWLEDGE ORGANIZATION CONGRESS, 8., 2007, León (España). Actas... Léon: Universidad de León, 2007. p. 399-409.

KUMAR, K. Theory of classification. 2nd ed. rev. New Delhi: Vikas Publishing House, 1981.

LANGRIDGE, D. Classificação: abordagem para estudantes de biblioteconomia. Rio de Janeiro: Interciência, 1977.

LARAIA, R. B. Cultura: um conceito antropológico. Rio de Janeiro: Jorge Zahar. 2006. 
LIMA, G. Â. B. O modelo simplificado para análise facetada de Spiteri a partir de Ranganathan e do Classification Research Group (CRG). Información, Cultura y Sociedad, Buenos Aires, n. 11, p. 57-72, 2004.

LOUREIRO, J. J. P. A questão cultural amazônica. In: SECRETARIA DE ESTADO DO PARÁ. Estudos e problemas amazônicos: história social e econômica e temas especiais. 2. ed. Belém: CEJUP, 1992.

MAUÉS, R. H. Uma outra "invenção" da Amazônia: religiões, histórias, identidades. Belém: Cejup, 1999.

MORAES, A. F.; ARCELLO, E. N. O conhecimento e sua representação. Informação e Sociedade, João Pessoa, v. 10, n. 2, p. 1-11, 2000.

NOVO, H. A elaboração de taxonomia: princípios classificatórios para domínios interdisciplinares. 2007. 172 f. Dissertação (Mestrado em Ciência da Informação). Instituto de Artes e Comunicação Social da Universidade Federal Fluminense/ Instituto Brasileiro de Informação em Ciência e Tecnologia, Niterói, 2007.

A taxonomia enquanto estrutura classificatória: uma aplicação em domínio de conhecimento interdisciplinar. Ponto de Acesso, Salvador, v. 4, n. 2, p.131-156, set. 2010. Disponível em: <www.pontodeacesso.ici.ufba.br>. Acesso em: 22 dez. 2010.

NUNES, B. Um conceito de cultura. Belém: Conselho Estadual de Cultura, 2004.

OLIVEIRA, M. O. E. Vocabulário terminológico cultural da Amazônia Paraense: com termos da área de Castanhal. Belém: EDUFPA, 2005a. v. 2.

- Vocabulário terminológico cultural da Amazônia Paraense: com termos da área de Bragança. Belém: EDUFPA, 2005b. v. 3.

- Vocabulário terminológico cultural da Amazônia Paraense: com termos da área do Marajó. Belém: Alves, 2010. v. 4.

RANGANATHAN, S. R. Prolegomena to library classification. Bombay: Asia Publishing House, 1967 apud CAMPOS, M. L. A. A organização de unidades de conhecimento em hiperdocumentos: o modelo conceitual com um espaço comunicacional para realização da autoria. 2001. 171 f. Tese (Doutorado em Ciência da Informação). Escola de Comunicação da Universidade Federal do Rio de Janeiro, Rio de Janeiro, 2001.

SCHREINER, H. B. Considerações históricas acerca do valor das classificações bibliográficas. In: CONFERÊNCIA BRASILEIRA DE CLASSIFICAÇÃO BIBLIOGRÁFICA, 1., 1976, Rio de Janeiro. Anais... Rio de Janeiro: IBICT, 1979. p.190-207.

SMIT, J. W.; TÁLAMO, M. F. G. M.; KOBASHI, N. Y. A determinação do campo científico da Ciência da Informação: uma abordagem terminológica. DataGramaZero - Revista de Ciência da Informação, v. 5, 
n. 1, fev. 2004. Disponível em: <http://www.dgz.org.br>. Acesso em: 12 out. 2006.

SPITERI, L. F. The classification research group and the theory of integrative levels. The Katharine Sharp Review, n.1, summer, 1995.

THOMPSON, J. B. Ideologia e cultura moderna. Petrópolis: Vozes, 1995.

VERÍSSIMO, J. Estudos amazônicos. Belém: Universidade Federal do Pará, 1970.

WILLIAMS, R. Cultura. 3 ed. Rio de Janeiro: Paz e Terra, 2008.

WILSON, T. 'Information Science' and research methods. 2002, p.63-71. Disponível em: <http:informationr.net/tdw/publ/papers/sloval02.htm>. Acesso em: 10 dez. 2010. 